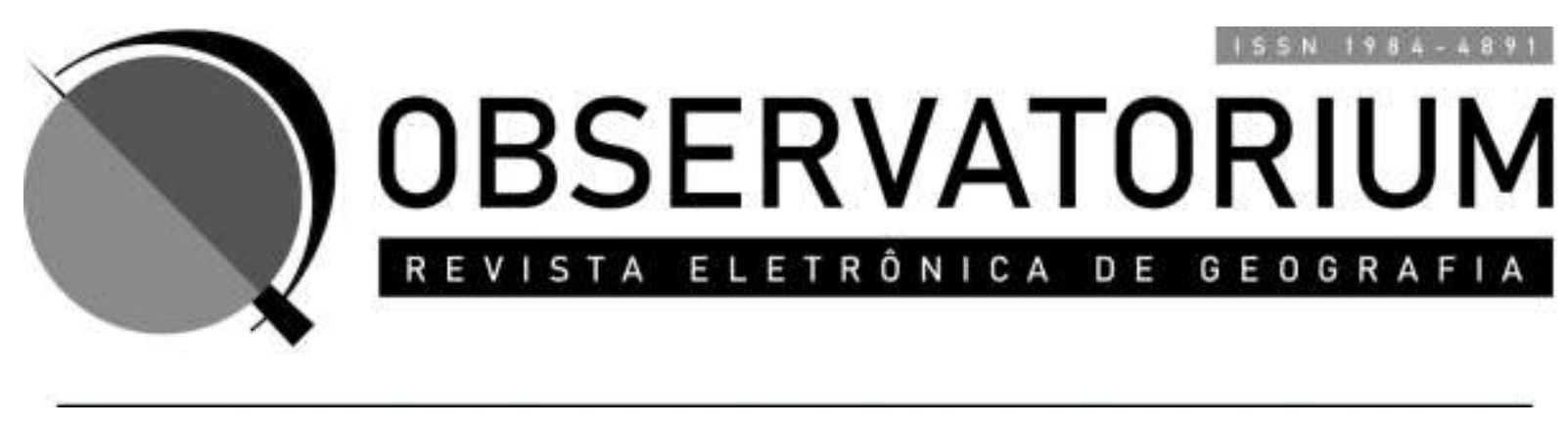

\title{
A EXPANSÃo dO CULTIVO DE CANA DE AÇÚCAR NA MICRORREGIÃo DE UBERABA E A PRODUÇÃo DE LEITE ${ }^{1}$
}

THE EXPANSION OF SUGAR CANE CULTIVATION IN THE UBERABA MICRO-REGION AND

MILK PRODUCTION

Celso Vitor Tamborin ${ }^{2}$

Rosselvelt José Santos3

\section{RESUMO}

A reflexão que segue tem como objetivo discutir as dinâmicas socioespaciais da produção de leite no contexto da expansão canavieira na microrregião de Uberaba, localizado na mesorregião do Triângulo Mineiro/Alto Paranaíba no Estado de Minas Gerais. Neste propósito, o texto traz informações sobre os processos de cultivo das lavouras de cana-de-açúcar na área de estudo. Analisamos os processos de reocupação das áreas agricultáveis, identificando as transformações e impactos socioeconômicos na área de estudo. Os dados produzidos pelo IBGE foram organizados por município considerando a produção de cana-de-açúcar e da agropecuária leiteira entre os anos de 2006 a 2016, pois trata-se de um período de importantes transformações socioprodutivas na microrregião. As mutações no espaço indicam a territorialização do setor sucroalcooleiro. Na exposição dos resultados da pesquisa discutimos as práticas do agronegócio e o surgimento de paisagens homogêneas, principalmente nos municípios onde se encontram instaladas as plantas das usinas processadoras de cana. Com relação a pecuária leiteira, o leite produzido nas propriedades rurais dos municípios que compõem a microrregião, em geral, apresentou, no período analisado queda considerável, sendo possível relacionar essa diminuição com a expansão ao monocultivo da cana-de-açúcar.

PALAVRAS-CHAVE: Cana-de-açúcar, Pecuária leiteira, Territorialização.

\footnotetext{
${ }^{1} \mathrm{O}$ texto resulta da pesquisa de Iniciação Cientifica de Celso Vítor Tamborin coordenado por Rosselvelt José Santos, com auxílio financeiro da Fundamentação de Amparo à Pesquisa de Minas Gerais Fapemig (APQ-03010-16), que agradecemos fortemente.

2 Graduando em Geografia pela Universidade Federal de Uberlândia (UFU) e bolsista do PET SESu/MEC do curso de Geografia do Instituto de Geografia - IG -UFU. E-mail: celso.tamborin2@gmail.com

3 Professor Doutor do Instituto de Geografia- UFU. E-mail: rosselvelt@ufu.br
} 


\begin{abstract}
The following reflection aims to discuss the socio-spatial dynamics of milk production in the context of the sugarcane expansion in the Uberaba microregion, located in the Triângulo Mineiro / Alto Paranaíba mesoregion in the State of Minas Gerais. In this regard, the text provides information on the cultivation processes of sugarcane crops in the study area. We analyzed the processes of reoccupation of agricultural areas, identifying the socioeconomic changes and impacts in the study area. The data produced by IBGE were organized by municipality considering the production of sugarcane and dairy farming between 2006 and 2016, as this is a period of important socio-productive transformations in the micro-region. Changes in space indicate the territorialization of the sugar and alcohol sector. In the presentation of the research results, we discussed the practices of agribusiness and the emergence of homogeneous landscapes, especially in the municipalities where the plants of the sugarcane processing plants are installed. With regard to dairy farming, the milk produced in the rural properties of the municipalities that make up the micro-region, in general, presented a considerable drop in the analyzed period, being possible to relate this decrease with the expansion to the sugarcane monoculture.
\end{abstract}

KEYWORDS: Sugarcane, Dairy Cattle, Territorialization.

\title{
INTRODUÇÃO
}

A dinâmica socioespacial da expansão canavieira ocorrida no início do século XXI, na microrregião de Uberaba, no estado de Minas Gerais, indica o desenvolvimento de processos amplos implicados na reocupação do espaço. No contexto do agronegócio objetivamos analisar as desarticulações dos processos produtivos já existentes no espaço, bem como identificar as transformações socioeconômicas ocorridas naquela microrregião.

A Microrregião de Uberaba faz parte do Bioma Cerrado e encontra-se localizada na mesorregião do Triângulo Mineiro/ Alto do Paranaíba (Figura1), no estado de Minas Gerais. Esta região é composta por sete municípios, sendo estes: Uberaba, Conceição das Alagoas, Delta, Campo Florido, Conquista, Veríssimo e Água Comprida. Segundo o censo 2010 do Instituto Brasileiro de Geografia e Estatística (IBGE), a microrregião de estudo tem como área territorial 109.680,03 km² e uma população estimada em 346.024 habitantes. 


\section{Figura 1: Localização Microrregião de Uberaba}

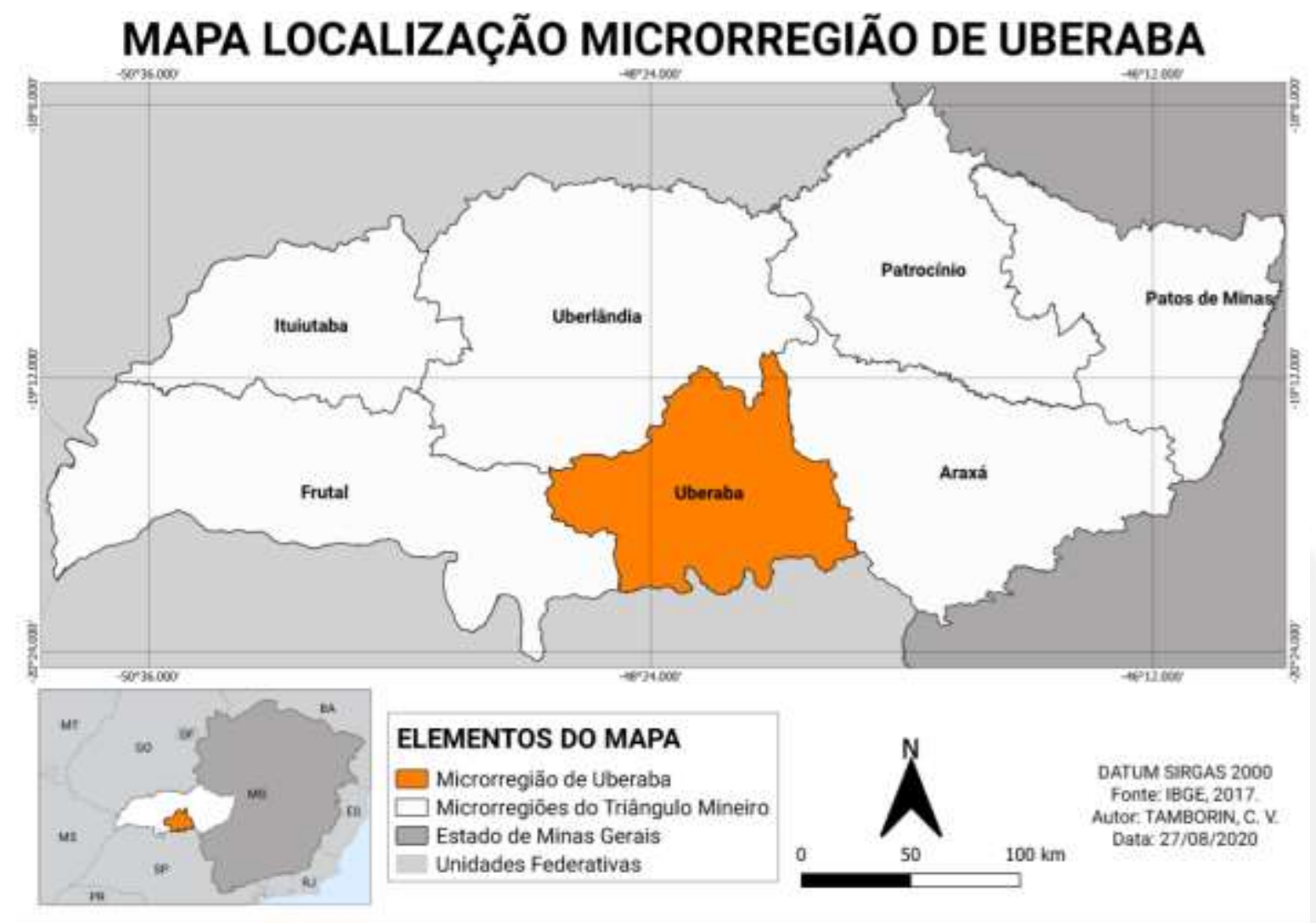

Fonte: IBGE, 2017. Organização: TAMBORIN, C. V.

A área de estudo se caracteriza por ser a maior produtora de cana-de-açúcar entre as microrregiões do estado de Minas Gerais. Considerado os dados disponibilizados pelo SIDRA-IBGE, a produção de cana-de-açúcar na microrregião de Uberaba em 2016 foi de 17.220 .818 toneladas, representando por volta de $24,65 \%$ da produção de todo estado naquele. Tal processo ocorre a partir de incentivos socioeconômicos realizados pelo Estado Brasileiro a partir da década de 1970. Destacam-se projetos como o Programa Nacional do Álcool - PROALCOOL, Programa de Desenvolvimento dos Cerrados - POLOCENTRO e Programa de Cooperação NipoBrasileira para o Desenvolvimento dos Cerrados PRODECER. Eles possibilitaram a reocupação do Cerrado tanto social, quanto tecnologicamente. Na microrregião, com a disponibilidade de tecnologia, melhoramento agronômico chega-se ao monocultivo de grãos e recentemente a cana-de-açúcar. 


\section{O CULTIVO DE CANA NA MICRORREGIÃO DE UBERABA}

O cultivo de cana-de-açúcar para produzir açúcar e logo a seguir álcool combustível em grandes áreas no território brasileiro iniciou-se logo após o final da Segunda Guerra mundial, sendo uma resposta à devastação das lavouras de cana da Europa em decorrência do conflito. Essa ação teve como objetivo, suprir a demanda mundial, inserindo esse produto brasileiro no mercado internacional. Apesar disso, o Brasil há muito tempo se destacou na produção dessa commodity:

Segundo Prado Jr. (1976), citado por Fausto, (2006) até o século XVII, o Brasil era o maior produtor mundial de açúcar. No Nordeste, do Recôncavo Baiano ao Rio Grande do Norte, cultivava-se cana-deaçúcar. Os núcleos principais de produção foram Bahia e Pernambuco. Rio de Janeiro e Espírito Santo cultivavam cana em menor escala e, de forma predominante, para a produção de aguardente que servia de moeda de troca por escravos na África. (BRITO, J. L. S, et al, 2012)

Segundo Zanzarini, R. M. \& Santos, R.J (2008) o Estado Brasileiro percebeu diante da crise do petróleo da década de 1970, possibilidades de se tornar, através da produção de cana-de-açúcar, influente internacionalmente. Neste contexto, o estado intervém internamente na situação agrária redefinindo a produção nacional que era voltada para grãos, ocasionando amplas imissões de recursos para o cultivo daquela gramínea perene.

Desse modo, o contexto histórico de inclusão da microrregião de Uberaba no cultivo da cana é relativo as ações do Estado no bioma Cerrado entre os anos de 1960 e 1980. Naquele período ocorreu a criação de programas de incentivos para o desenvolvimento agrícola, principalmente nos chapadões do Bioma.

Como já assinalado, os programas governamentais de maior relevância foram o POLOCENTRO e o PRODECER. Ambos foram essenciais para a reocupação da microrregião, bem como inclusão de novas tecnologias, modelos socioeconômicos de produção agropecuários na região do Triângulo Mineiro. Consequentemente a Microrregião de Uberaba também é induzida a obter maior qualidade na produção agrícola, com a disponibilidade de maquinários qualificados operarem em grandes lavouras, sementes adaptadas e insumos agrícolas.

Em 1975, foi criado PROALCOOL pelo governo federal brasileiro, que tinha como objetivo, incentivar a produção de biocombustível (álcool/etanol) a partir da cana-de-açúcar. Naquele contexto o país comparecia no cenário internacional oferendo alternativa à crise do petróleo, pois também desenvolvia motores movidos ao etanol. 
Os incentivos variavam desde a redução de impostos na produção de carros movidos a etanol, diminuição de impostos para o etanol em relação à gasolina e até mesmo financiamento de plantas de usinas sucroenergética e seus canaviais.

Segundo Carvalho (2009) esses programas - em especial o PLANALSUCAR e PROALCOOL - visavam modificar a produção brasileira do setor sucroalcooleiro, tornando-a competitiva frente ao mercado internacional e desenvolvendo-o como alternativa biológica, para fazer baixar a importação de petróleo.

Gonçalves (2009) considera que o Brasil tornou-se líder nas tecnologias de produção do etanol extraído da cana-de-açúcar ao se tornar responsável por $45 \%$ da produção mundial, feita em mais de 400 usinas e destilarias. Gonçalves (2009) ainda afirma que é sob o novo paradigma da sustentabilidade ambiental que o país avançou no desenvolvimento de técnicas de extração do etanol a partir da cana-de-açúcar. Assim, além de uma necessidade econômica derivada da oscilação dos preços do petróleo praticados internacionalmente, as questões ambientais também influenciaram decisivamente na produção de uma nova matriz energética.

Com o álcool abastecendo parte da frota, logo o Brasil conquistou autonomia em relação aos combustíveis. Objetivando a manutenção dessa condição, os programas governamentais de incentivo a produção e transformação da cana-de-açúcar espalha a indústria de processamento de cana-de-açúcar por algumas regiões do país. No Triângulo Mineiro o cultivo da cana-de-açúcar assume destaque socioeconômico. Segundo a secretaria do Estado e Desenvolvimento Econômico do Governo de Minas Gerais, o estado na primeira década do século XXl recebeu cerca de 211 milhões em investimentos para o setor sucroalcooleiro.

O estado de Minas Gerais é o terceiro maior produtor de cana-de-açúcar do Brasil. Em 2020 11,1\% da produção brasileira foi colhida no território mineiro, ficando atrás do estado de São Paulo e Goiás (SEAPA, 2020). O Triângulo Mineiro/ Alto Paranaíba, onde se encontra a microrregião de Uberaba, é responsável por grande parte dessa produção. Em 2016, de acordo com dados da Produção Agrícola Municipal - PAM (SIDRA/IBGE), Minas Gerais produziu cerca de 69.934.887 toneladas de canade-açúcar. Na mesma safra, a microrregião de Uberaba, produziu 17.220.818 tonelada, tornando-se responsável por 24,64\% da produção total do estado mineiro em 2016.

Assim podemos afirmar que as politicas públicas voltadas para a produção e transformação da cana-de açúcar chegaram e transformaram as paisagens da 
macrorregião do Triângulo Mineiro/Alto do Paranaíba e consequentemente microrregião de Uberaba:

No tocante à agroindústria canavieira, desde meados da década de 1990, as regiões do Triângulo Mineiro/Alto Paranaíba vêm recebendo fortes incentivos públicos e privados, no setor sucroalcooleiro. Assim, no estado de Minas Gerais, os investimentos para ampliação da atividade sucroalcooleira, como a criação e melhoria das unidades, são resultantes de investimentos de diversos setores produtivos. (CARVALHO, 2009, p. 74)

Além de políticas públicas devemos considerar a qualidade dos solos e clima favorável. Eles também entusiasmam a quantidade e qualidade da produção de canade-açúcar naquela área, pois:

O Estado de Minas Gerais também apresenta condições naturais que convergem em favor do cultivo da cana-de-açúcar, especialmente no Triângulo Mineiro/Alto Paranaíba, uma vez que os dados do zoneamento agroclimático do estado caracterizam o solo da região como de aptidão regular nos níveis de manejo B e C. isto é, o segundo e terceiro melhor solo para cultivo, havendo uma vasta área contínua do nível C para produção agrícola no estado. De acordo com esses dados, são "aptos" e de melhor adequação à cultura da cana, os solos das regiões oeste de Minas Gerais e Triângulo Mineiro/Alto Paranaíba. Além disso, o clima tropical, com inverno seco e frio e verão quente e chuvoso, também viabiliza o desenvolvimento da monocultura na região, tendo em vista seu comportamento pluviométrico que apresenta, no saldo de precipitações anuais, uma variação de 1200 a 1500 milímetros, identificado como adequado para o cultivo de soja e cana-de-açúcar. Aliados às condições naturais favoráveis, Minas Gerais possui custos de produção inferiores aos do Estado de São Paulo, principalmente no que tange ao arrendamento de terra. (DE SOUZA, A. G. et al, 2009, p.14)

Os sete municípios que compõem a microrregião (Figura 2), são: Uberaba, Conceição das Alagoas, Delta, Campo Florido, Conquista, Veríssimo e Água Comprida. $\mathrm{Na}$ área são seis usinas sucroalcooleiras em operação. No conjunto, no ano de 2016, de acordo com o SIDRA-IBGE são 208,717 hectares de área ocupada com cana-deaçúcar, produzindo cerca de 17.220 .818 toneladas. 
Figura 2: Localização dos Municípios da Microrregião De Uberaba MAPA LOCALIZAÇÃO DOS MUNICÍPIOS DA MICRORREGIÃO DE UBERABA

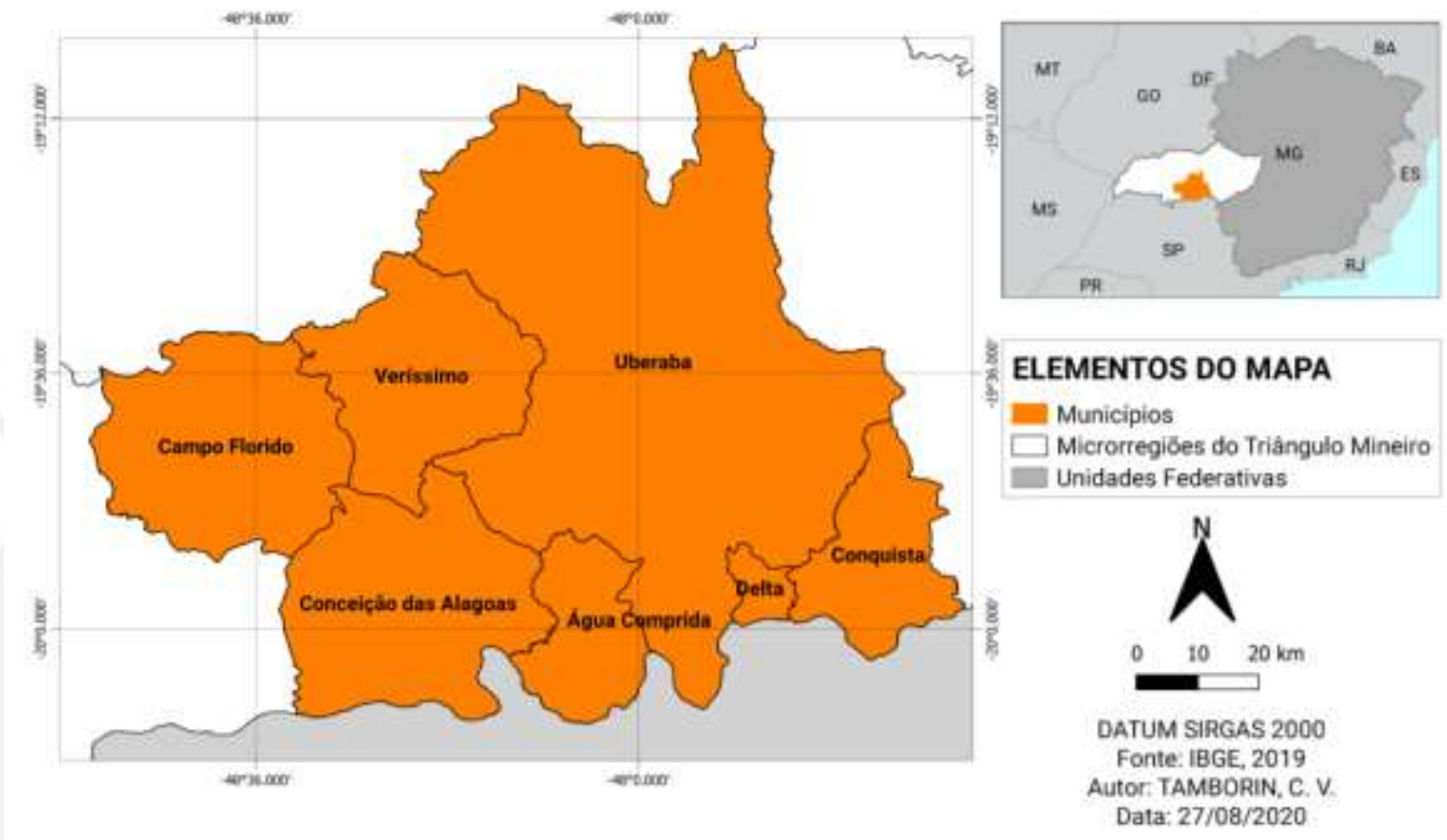

Fonte: IBGE, 2017. Organização: TAMBORIN, C. V.

\subsection{USINAS SUCROALCOOLEIRAS EM OPERAÇÃO NA MICRORREGIÃO DE UBERABA -MG}

Consideramos nesta exposição a origem e o ano de funcionamento das usinas, pois elas se constituem em importantes atores no processo de reocupação do espaço e territorialização das forças socioprodutivas ligadas ao setor sucroalcooleiro.

\subsubsection{Delta Sucroenergia}

O Grupo Delta Sucroenergia é composto por três unidades na microrregião de Uberaba. A Unidade Delta encontra-se localizada no município de Delta-MG. Ela foi fundada em 1950 e reformulada em 2000. A Unidade Volta Grande, fundada em 1996 tem sua planta industrial fixada no município de Conceição das Alagoas-MG. A terceira Unidade, inaugurada em 2011, localiza-se no município de Conquista- MG. 
De acordo com a Associação das Indústrias Sucroenergéticas de Minas Gerais, SIAMIG, (2018), o grupo Delta trabalha com a produção de açúcar, etanol, bioenergia e levedura (produto exportado para mercados externos, principalmente para criadores de bovinos, suínos, caprinos e frangos). O Grupo Delta Sucroenergia tem sua sede na cidade de São Paulo -SP

Essas unidades produziram na safra 2017/2018 mais de 907 mil toneladas de açúcar, 288 mil metros cúbicos de etanol e cerca de 500 mil mega watt-hora de energia, conforme a SIAMIG, 2018.

\subsubsection{Usina Coruripe Açúcar E Álcool S/A}

A Usina Coruripe Açúcar e Álcool S/A, faz parte do grupo Tércio Wanderley, que tem sede no Estado de Alagoas-AL e conta com quatro unidades em Minas Gerais, nos seguintes municípios: Iturama, Limeira do Oeste e Carneirinho, e na microrregião de Uberaba, no município de Campo Florido.

A Unidade de Campo Florido foi inaugurada no ano de 2005. No site oficial da Usina Coruripe Açúcar e Álcool S/A, ela conta com uma capacidade Instalada de processamento de 4,2 milhões de Toneladas de cana-de-açúcar.

\subsubsection{A Usina Uberaba S.A}

Ela faz parte do grupo empresarial Balbo, e se localiza no munícipio de Uberaba-MG. Ela foi inaugurada no ano de 2005. O site oficial da Usina informa que a mesma reúne capacidade de moagem de 2,100 milhões de toneladas por safra. Na safra de 2016/2017, foi produzido cerca de 334.382.000,oo litros de Etanol, 263,363.600 toneladas de açúcar e 10.462,09 MW/h de energia.

\subsubsection{Usina Vale Do Tijuco}

Pertence à Companhia Mineira de Açúcar e Álcool - CMAA, ela reporta-se a um grupo de capital aberto com sede em Jacarta na Indonésia. Localizada na Cidade de Uberaba-MG, sua inauguração ocorreu em 2010. A planta industrial possui capacidade de moagem aproximadamente de 4,5 milhões de toneladas de cana-de- 
açúcar por safra. Atualmente produz-se açúcar, etanol anidro, etanol hidratado e energia elétrica, bem como os seguintes subprodutos: óleo fusel e bagaço de cana.

\section{TERRITORIALIZAÇÃO DA COMODITIES CANA-DE-ACÚCAR NA MICRORREGIÃO DE UBERABA-MG}

A cana-de-açúcar nos dados do IBEGE/SIDRA é considerada como lavouras temporárias e medida em hectares (ha). Em cada um dos municípios da microrregião de Uberaba, consideramos além da área a quantidade produzida em toneladas ( $\mathrm{t}$ ), levando em consideração o recorte temporal anteriormente definido, 2006 a 2016.

Inácio, J. B \& Santos, R.J, 2014, afirmam que:

Os cultivos apresentados são classificados pelo IBGE como lavouras temporárias, porém, em determinadas regiões do Brasil, operam em alta e fazem parte da produção agrícola permanente, mas também podem apresentar quedas, conforme o balanço comercial que estipula os custos e preços dos produtos e os critérios econômicos (INÁCIO, J.B. et al, 2014, p.45).

Os autores também compreendem que o agronegócio, movido pelas políticas públicas e pelos rendimentos economicos, vão fazendo surgir maciçamente nas paisagens da região uma lavoura homogênea, com traçados retilíneos que empregam várias tecnologias.

\subsection{UBERABA}

De acordo com os dados do IBGE Cidades (2019), o munícipio de Uberaba-MG tem uma área territorial de 4.523,957 km² . Conforme as informações do SIDRA-IBGE, esse municipio teve no ano de 2006 uma área plantada de $360 \mathrm{~km}^{2}$. No entanto, em 2016 o cultivo da cana-de-açúcar amplia a sua área, atingindo 737,20 km². A quantidade produzida passou de 3.060.000 toneladas em 2006, para 6.267.158 toneladas em 2016. 
Gráfico 1: Comparação de área plantada (hectares) de Cana-de-Açúcar - Uberaba -2006/2016. Fonte: Produção Agrícola Municipal, IBGE, 2019. Organização: TAMBORIN, C. V.

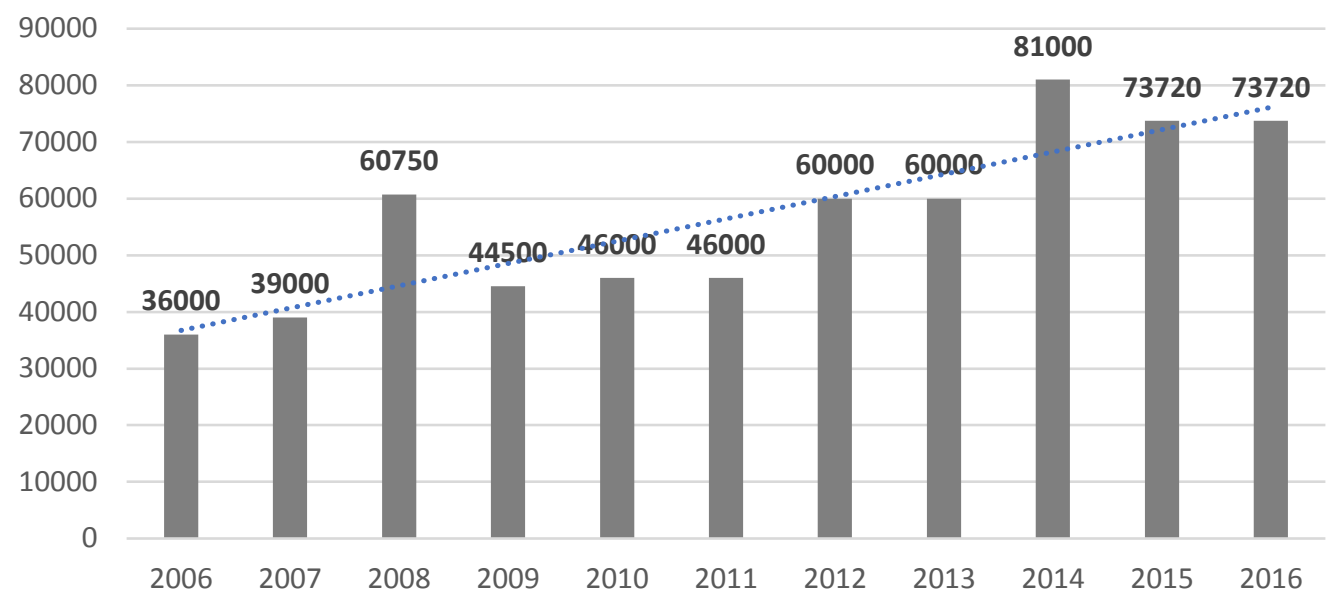

Tabela 1: Área plantada de Cana-de-Açúcar - Uberaba 2006/2016.

\begin{tabular}{c|c}
\hline & $\begin{array}{c}\text { ÁREA } \\
\text { ANO }\end{array}$ \\
\hline 2006 & 36000 \\
\hline 2007 & 39000 \\
\hline 2008 & 60750 \\
\hline 2009 & 44500 \\
\hline 2010 & 46000 \\
\hline 2011 & 46000 \\
\hline 2012 & 60000 \\
\hline 2013 & 60000 \\
\hline 2014 & 81000 \\
\hline 2015 & 73720 \\
\hline 2016 & 73720 \\
\hline
\end{tabular}

Fonte: Produção Agrícola Municipal, IBGE, 2019.

Organização: TAMBORIN, C. V. 
Tabela 2: Produção de Cana-de-Açúcar - Uberaba - 2006/2016.

\begin{tabular}{c|c}
\hline ANO & QUANTIDADE PRODUZIDA (TONELADAS) \\
\hline 2006 & 3060000 \\
\hline 2007 & 3315000 \\
\hline 2008 & 5467500 \\
\hline 2009 & 4227500 \\
\hline 2010 & 4370000 \\
\hline 2011 & 4370000 \\
\hline 2012 & 5700000 \\
\hline 2013 & 5700000 \\
\hline 2014 & 6885000 \\
\hline 2015 & 6266200 \\
\hline 2016 & 6267158 \\
\hline
\end{tabular}

Fonte: Produção Agrícola Municipal, IBGE, 2019. Organização: TAMBORIN, C. V.

Observa-se no período analisado que tanto a área cultivada quanto a quantidade de cana-de-açúcar produzida tiveram um aumento substancial, sendo 104,8\% para a área em km² e 105\% para a produção em toneladas.

\subsection{CONCEIÇÃO DAS ALAGOAS}

Conceição das Alagoas-MG apresenta área territorial de $1.340,250 \mathrm{~km}^{2}$. O município teve em 2006, uma área plantada de aproximadamente $290 \mathrm{~km}^{2}$ de canade-açúcar, em 2016, esse valor passou para $450 \mathrm{~km}^{2}$. A quantidade de cana-de-açúcar produzida passou de 2320000 toneladas em 2006, para 3600000 toneladas em 2016. 
Gráfico 2: Comparação de área plantada (hectares) de Cana-de-açúcar Conceição das Alagoas - 2006/2016.

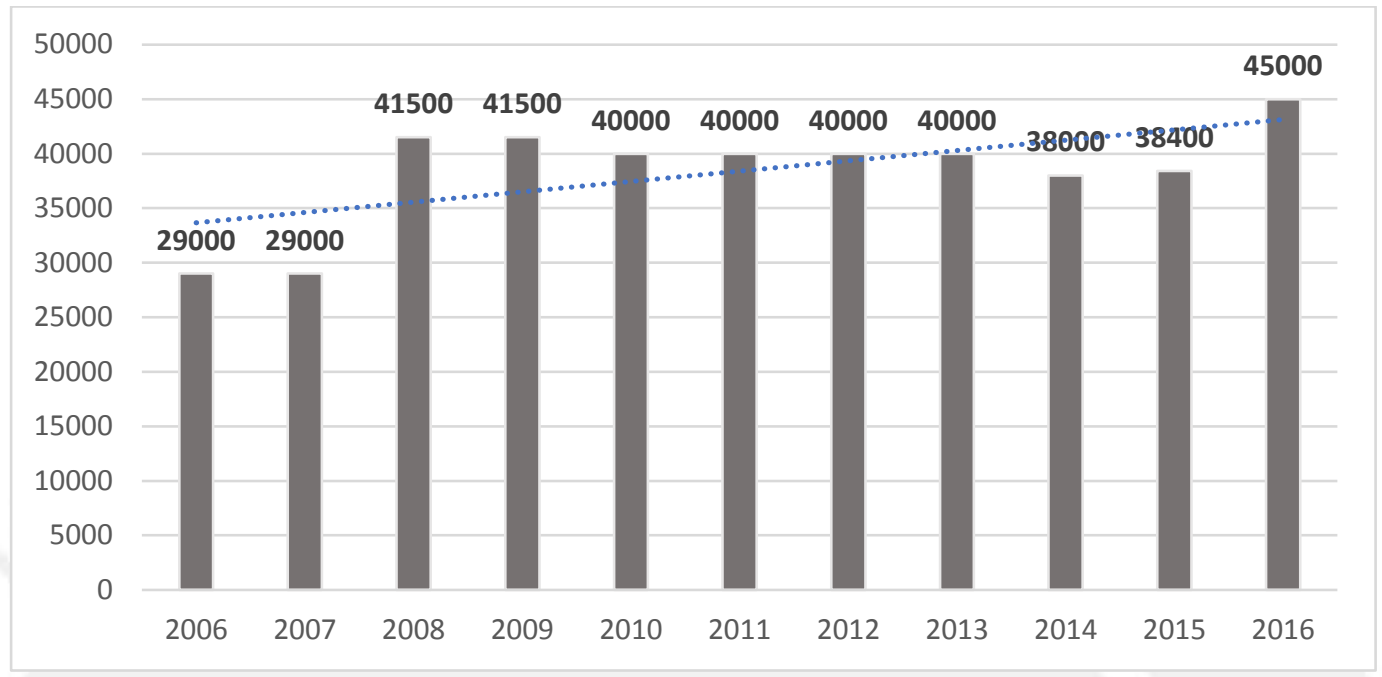

Fonte: Produção Agrícola Municipal, IBGE, 2019. Organização: TAMBORIN, C. V.

Tabela 3: Área plantada de Cana-de-Açúcar - Conceição das Alagoas - 2006/2016

\begin{tabular}{l|l}
\hline ANO & ÁREA PLANTADA (hectares) \\
\hline 2006 & 29000 \\
\hline 2007 & 29000 \\
\hline 2008 & 41500 \\
\hline 2009 & 41500 \\
\hline 2010 & 40000 \\
\hline 2011 & 40000 \\
\hline 2012 & 40000 \\
\hline 2013 & 40000 \\
\hline 2014 & 38000 \\
\hline 2015 & 38400 \\
\hline 2016 & 45000 \\
\hline
\end{tabular}

Fonte: Produção Agrícola Municipal, IBGE, 2019. Organização: TAMBORIN, C. V. 
Tabela 4: Produção de Cana-de-Açúcar - Conceição das Alagoas - 2006/2016

\begin{tabular}{c|c}
\hline ANO & QUANTIDADE PRODUZIDA (TONELADAS) \\
\hline 2006 & 2320000 \\
\hline 2007 & 2320000 \\
\hline 2008 & 3320000 \\
\hline 2009 & 3984000 \\
\hline 2010 & 3840000 \\
\hline 2011 & 3840000 \\
\hline 2012 & 3800000 \\
\hline 2013 & 3800000 \\
\hline 2014 & 3040000 \\
\hline 2015 & 3072000 \\
\hline 2016 & 3600000 \\
\hline
\end{tabular}

Fonte: Produção Agrícola Municipal, IBGE, 2019. Organização: TAMBORIN, C. V.

Ressalta-se que no tempo analisado, tanto a área cultivada quanto a quantidade de cana-de-açúcar produzida teve acréscimos importantes, sendo $55 \%$ para a área em km² e 55,17\% para a produção em toneladas.

\subsection{DELTA}

Delta abranger uma área territorial de 102,784 km². Em 2006, o municipio somava uma área plantada de 60km² de cana-de-açúcar, já em 2006, o valor em área plantada diminuiu para 52,97 $\mathrm{km}^{2}$. A quantidade de cana-de-açúcar produzida reduziu de 480000 toneladas em 2006 para 423760 tonaladas em 2016. 
Gráfico 3: Comparação de área plantada (hectares) de Cana-de-Açúcar - Delta $2006 / 2016$

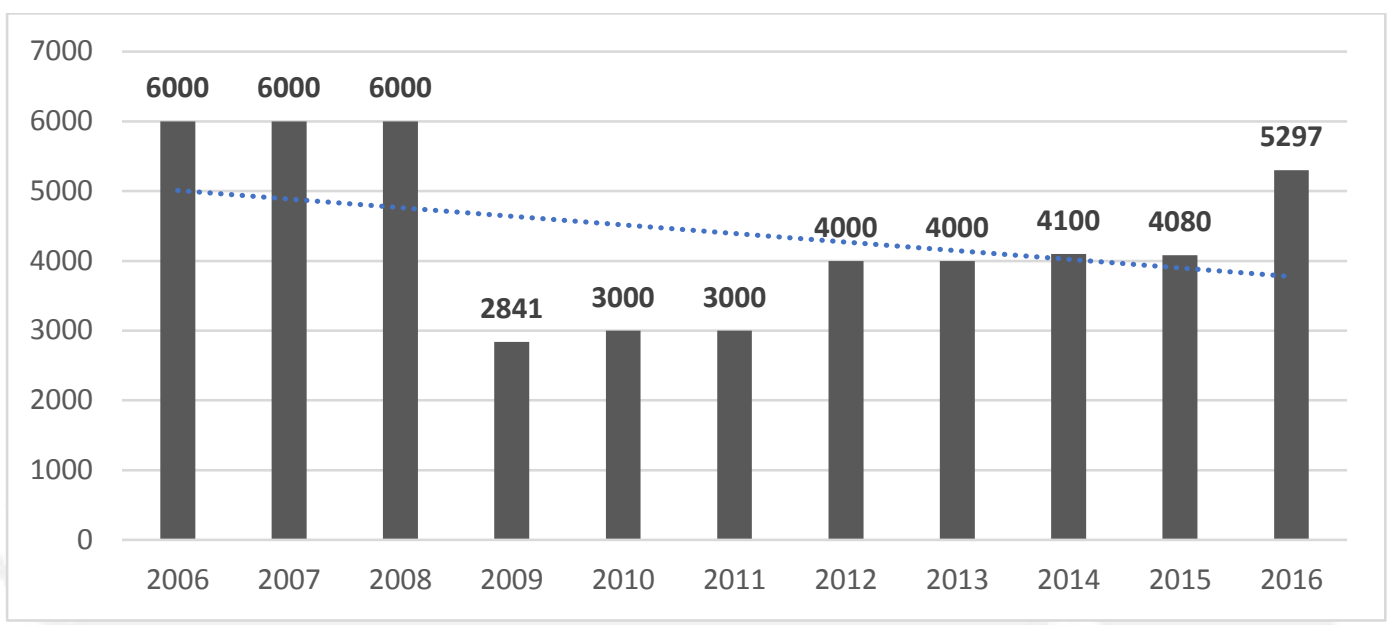

Fonte: Produção Agrícola Municipal, IBGE, 2019. Organização: TAMBORIN, C. V.

Tabela 5: Área plantada de Cana-de-Açúcar - Delta - 2006/2016.

\begin{tabular}{c|c}
\hline ANO & ÁREA PLANTADA (hectares) \\
\hline 2006 & 6000 \\
\hline 2007 & 6000 \\
\hline 2008 & 6000 \\
\hline 2009 & 2841 \\
\hline 2010 & 3000 \\
\hline 2011 & 3000 \\
\hline 2012 & 4000 \\
\hline 2013 & 4000 \\
\hline 2014 & 4100 \\
\hline 2015 & 4080 \\
\hline 2016 & 5297 \\
\hline
\end{tabular}

Fonte: Produção Agrícola Municipal, IBGE, 2019. Organização: TAMBORIN, C. V.

Tabela 6: Produção de Cana-de-Açúcar - Delta - 2006/2016

\begin{tabular}{c|c}
\hline ANO & QUANTIDADE PRODUZIDA (TONELADAS) \\
\hline 2006 & 480000 \\
\hline 2007 & 480000 \\
\hline 2008 & 480000 \\
\hline 2009 & 252034 \\
\hline 2010 & 270000 \\
\hline
\end{tabular}




\begin{tabular}{l|l}
\hline 2011 & 270000 \\
\hline 2012 & 360000 \\
\hline 2013 & 360000 \\
\hline 2014 & 332100 \\
\hline 2015 & 330480 \\
\hline 2016 & 423760 \\
\hline
\end{tabular}

Fonte: Produção Agrícola Municipal, IBGE, 2019. Organização: TAMBORIN, C. V.

Destaca-se que nos 11 anos analisados, tanto a área cultivada quanto a quantidade de cana-de-açúcar produzida teve uma pequena queda, registrando menos $13,28 \%$ para as duas situações.

\subsection{CAMPO FLORIDO}

Trata-se de um municipio com área territorial de $1.264,245 \mathrm{~km}^{2}$. No ano de 2006, a área plantada de cana-de-açúcar era de $185 \mathrm{~km}^{2}$. Em 2016, esse valor atinge $260 \mathrm{~km}^{2}$. A quantidade de cana-de-açúcar produzida passou de 1757500 tonaladas em 2006 para 2340000 toneladas em 2016.

Gráfico 4: Comparação de área plantada (hectares) de Cana-de-Açúcar - Campo Florido - 2006/2016

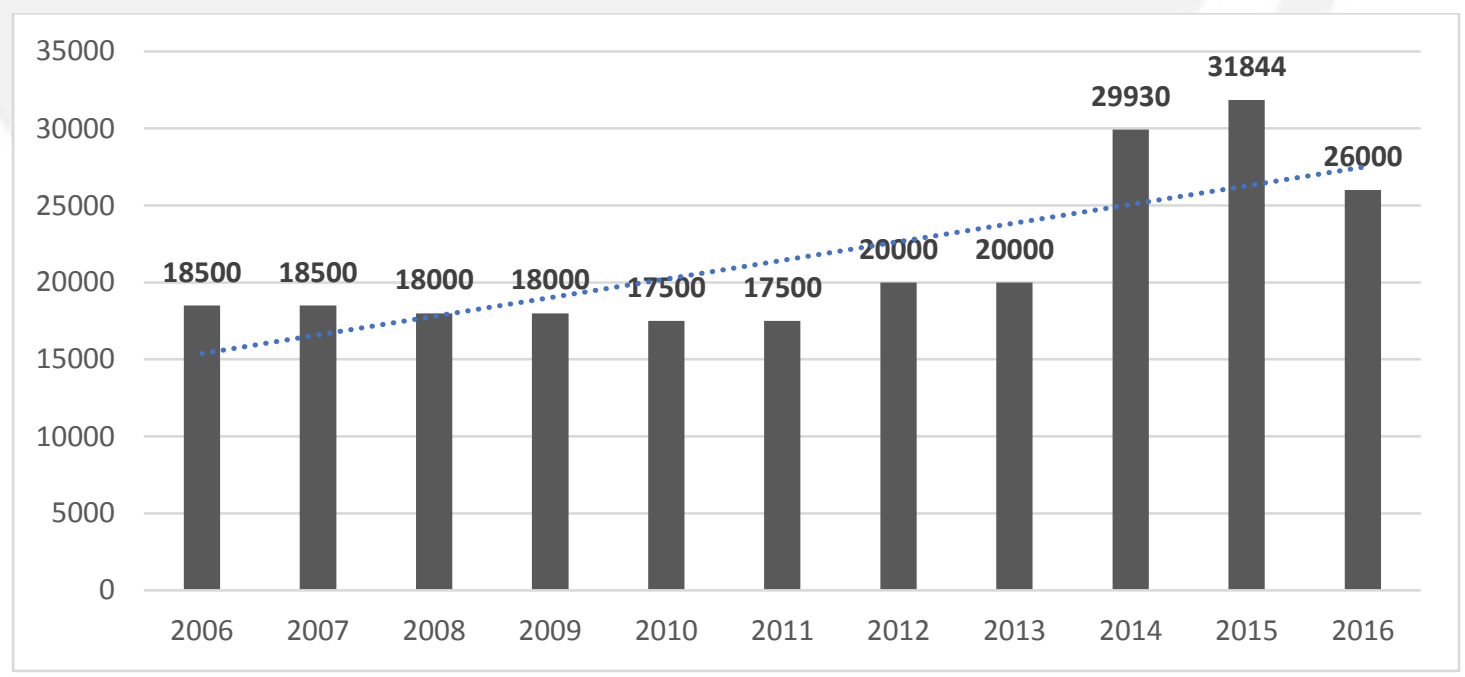

Fonte: Produção Agrícola Municipal, IBGE, 2019. Organização: TAMBORIN, C. V. 
Tabela 6: Área plantada de Cana-de-Açúcar - Campo Florido - 2006 e 2016.

\begin{tabular}{c|c}
\hline ANO & ÁREA PLANTADA (hectares) \\
\hline 2006 & 18500 \\
\hline 2007 & 18500 \\
\hline 2008 & 18000 \\
\hline 2009 & 18000 \\
\hline 2010 & 17500 \\
\hline 2011 & 17500 \\
\hline 2012 & 20000 \\
\hline 2013 & 20000 \\
\hline 2014 & 29930 \\
\hline 2015 & 31844 \\
\hline 2016 & 26000 \\
\hline
\end{tabular}

Fonte: Produção Agrícola Municipal, IBGE, 2019. Organização: TAMBORIN, C. V.

Tabela 7 Quantidade produzida de Cana-de-Açúcar- Campo Florido - 2006 e 2016.

\begin{tabular}{c|c}
\hline ANO & QUANTIDADE PRODUZIDA (TONELADAS) \\
\hline 2006 & 1757500 \\
\hline 2007 & 1757500 \\
\hline 2008 & 1728000 \\
\hline 2009 & 1800000 \\
\hline 2010 & 1750000 \\
\hline 2011 & 1750000 \\
\hline 2012 & 1800000 \\
\hline 2013 & 1800000 \\
\hline 2014 & 2439295 \\
\hline 2015 & 2595286 \\
\hline 2016 & 2340000 \\
\hline
\end{tabular}

Fonte: Produção Agrícola Municipal, IBGE, 2019. Organização: TAMBORIN, C. V. 
Adverte-se que no período analisado, tanto a área cultivada quanto a quantidade de cana-de-açúcar produzida registram aumentos, sendo 40,60\% para a área em km² e 33,15\% para a produção em toneladas.

\subsection{CONQUISTA}

Munícipio de Colonização Italiana expõe uma área territorial de 618,363 km². No ano de 2006 registrou área plantada de 98 km² de cana-de-açúcar. Em 2016, esse valor passou para $212 \mathrm{~km}^{2}$. Com relação a quantidade de cana-de-açúcar produzida passou de 735000 tonaladas em 2006 para 1844400 toneladas em 2016.

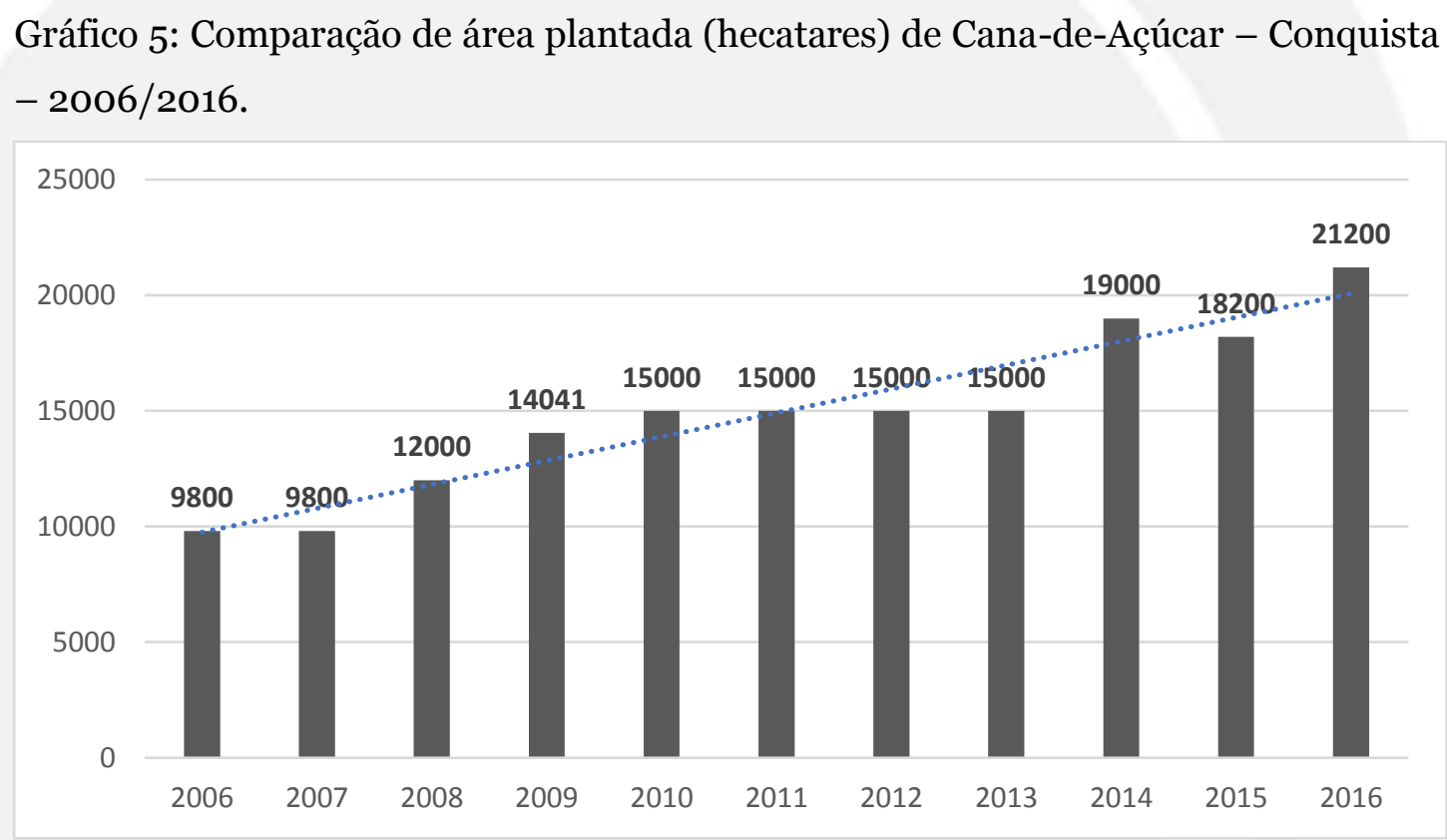

Fonte: Produção Agrícola Municipal, IBGE, 2019. Organização: TAMBORIN, C. V.

Tabela 8: Área plantada (hectares) de Cana-de-Açúcar - Conquista - 2006 /2016

\begin{tabular}{c|c}
\hline ANO & ÁREA PLANTADA (h) \\
\hline 2006 & 9800 \\
\hline 2007 & 9800 \\
\hline 2008 & 12000 \\
\hline 2009 & 14041 \\
\hline 2010 & 15000 \\
\hline
\end{tabular}




\begin{tabular}{l|l}
\hline 2011 & 15000 \\
\hline 2012 & 15000 \\
\hline 2013 & 15000 \\
\hline 2014 & 19000 \\
\hline 2015 & 18200 \\
\hline 2016 & 21200 \\
\hline
\end{tabular}

Fonte: Produção Agrícola Municipal, IBGE, 2019. Organização: TAMBORIN, C. V.

Tabela 9: Quantidade produzida de Cana-de-Açúcar - Conquista - 2006/2016

\begin{tabular}{c|c}
\hline ANO & QUANTIDADE PRODUZIDA (TONELADAS) \\
\hline 2006 & 735000 \\
\hline 2007 & 735000 \\
\hline 2008 & 960000 \\
\hline 2010 & 1347936 \\
\hline 2011 & 1440000 \\
\hline 2012 & 1440000 \\
\hline 2013 & 1425000 \\
\hline 2014 & 1425000 \\
\hline 2015 & 1539000 \\
\hline 2016 & 1474200 \\
\hline
\end{tabular}

Fonte: Produção Agrícola Municipal, IBGE, 2019. Organização: TAMBORIN, C. V.

Nota-se que no período analisado, tanto a área cultivada quanto a quantidade de cana-de-açúcar produzida existem aumentos respeitáveis, sendo 116,33\% para a área em km² e 150,55\% para a produção em toneladas.

\subsection{VERÍSSIMO}

Veríssimo é um municipio que apresenta uma área territorial de $1.031,823 \mathrm{~km}^{2}$. No ano de 2006 tinha 4,8 km² de área plantada com cana-de-açúcar, 
já em 2006, esse quantitativo atinge $115 \mathrm{~km}^{2}$. A quantidade de cana-de-açúcar produzida passou de 38400 toneladas em 2006 para 977500 toneladas em 2016.

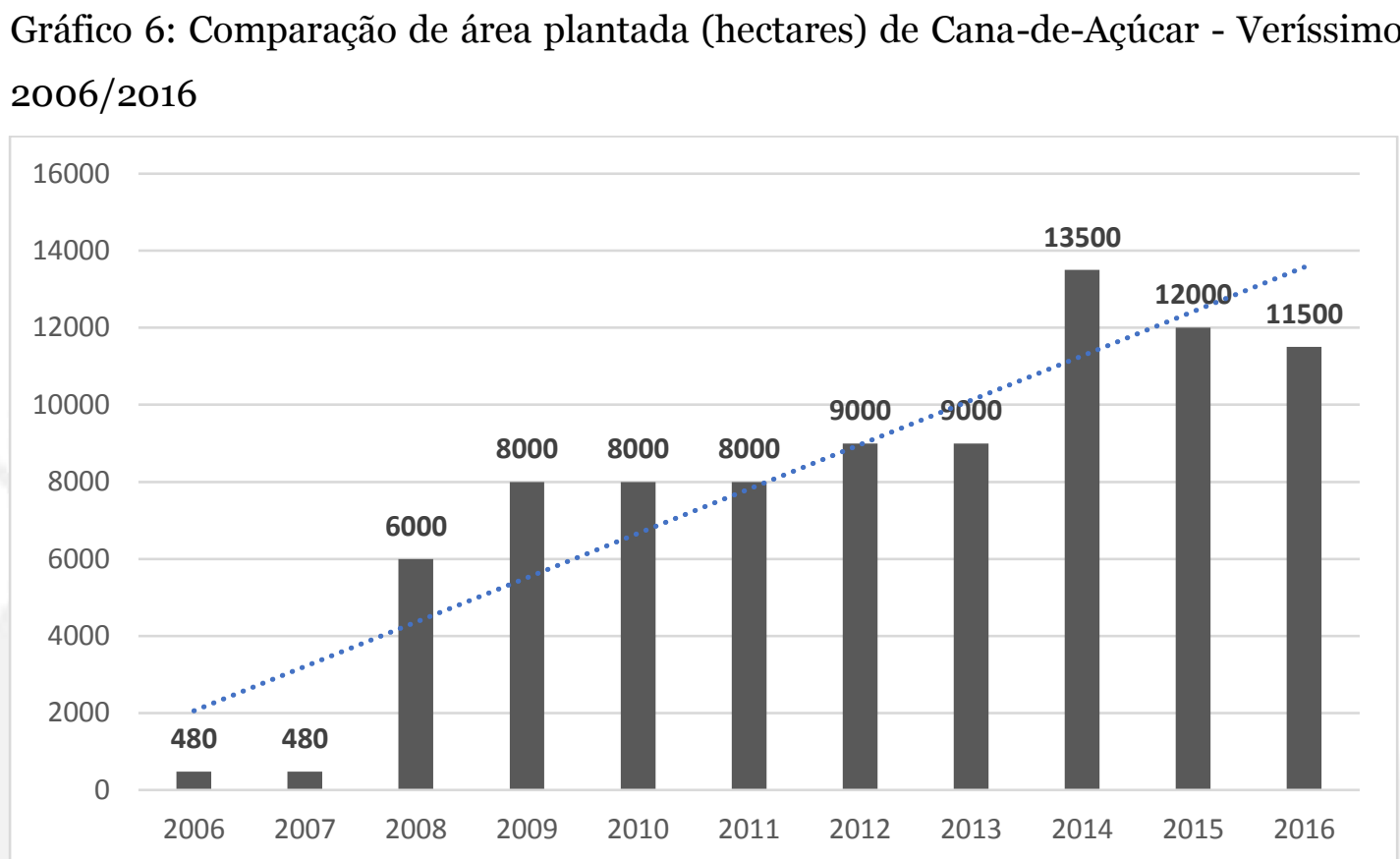

Fonte: Produção Agrícola Municipal, IBGE, 2019. Organização: TAMBORIN, C. V.

Tabela 10: Área plantada (hectares) de Cana-de-Açúcar - Veríssimo - 2006/2016

\begin{tabular}{c|c}
\hline ANO & ÁREA PLANTADA (hectares) \\
\hline 2006 & 480 \\
\hline 2007 & 480 \\
\hline 2008 & 6000 \\
\hline 2009 & 8000 \\
\hline 2010 & 8000 \\
\hline 2011 & 8000 \\
\hline 2012 & 9000 \\
\hline 2013 & 9000 \\
\hline 2014 & 13500 \\
\hline 2015 & 12000 \\
\hline 2016 & 11500 \\
\hline
\end{tabular}

Fonte: Produção Agrícola Municipal, IBGE, 2019. Organização: TAMBORIN, C. V. 
Tabela 11: Produção de Cana-de-Açúcar - Veríssimo - 2006/2016.

\begin{tabular}{c|c}
\hline ANO & QUANTIDADE PRODUZIDA (TONELADAS) \\
\hline 2006 & 38400 \\
\hline 2007 & 38400 \\
\hline 2008 & 420000 \\
\hline 2009 & 720000 \\
\hline 2010 & 720000 \\
\hline 2011 & 720000 \\
\hline 2012 & 810000 \\
\hline 2013 & 810000 \\
\hline 2014 & 1080000 \\
\hline 2015 & 960000 \\
\hline
\end{tabular}

Fonte: Produção Agrícola Municipal, IBGE, 2019. Organização: TAMBORIN, C. V.

No período analisado, tanto a área cultivada quanto a quantidade de cana-deaçúcar produzida tiveram ampliações relevantes, sendo $239,58 \%$ para a área em $\mathrm{km}^{2}$ e $392,83 \%$ para a produção em toneladas.

\section{7 ÁGUA COMPRIDA}

O munícipio de apresenta área territorial de 492,167 km². Para o ano de 2006, exibia uma área plantada 79,6 km² de cana-de-açúcar. Em 2016, a área plantada era de $260 \mathrm{~km}^{2}$. A quantidade de cana-de-açúcar produzida passou de 636800 tonaladas em 2006 para 1768000 toneladas em 2016. 
Gráfico 7: Comparação de área plantada (hectares) de Cana-de-Açúcar - Água Comprida $2006 / 2016$

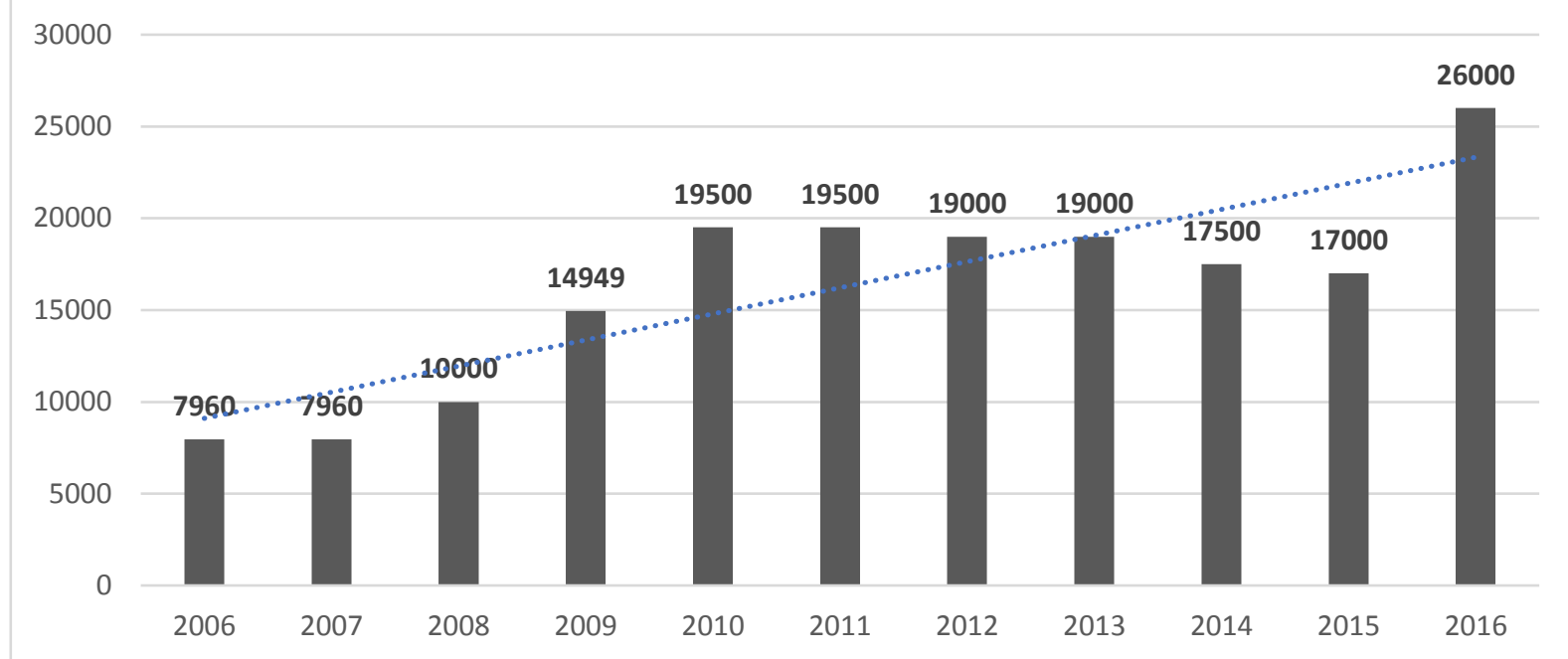

Fonte: Produção Agrícola Municipal, IBGE, 2019. Organização: TAMBORIN, C. V.

Tabela 12: Área plantada de Cana-de-Açúcar - Água Comprida -2006/2016

\begin{tabular}{c|c}
\hline ANO & ÁREA PLANTADA (hectares) \\
\hline 2006 & 7960 \\
\hline 2007 & 7960 \\
\hline 2008 & 10000 \\
\hline 2009 & 14949 \\
\hline 2010 & 19500 \\
\hline 2011 & 19500 \\
\hline 2012 & 19000 \\
\hline 2013 & 19000 \\
\hline 2014 & 17500 \\
\hline 2015 & 17000 \\
\hline 2016 & 26000 \\
\hline
\end{tabular}

Fonte: Produção Agrícola Municipal, IBGE, 2019. Organização: TAMBORIN, C. V. 
Tabela 13: Produção de Cana-de-Açúcar - Água Comprida -2006/2016.

\begin{tabular}{c|c}
\hline ANO & QUANTIDADE PRODUZIDA (TONELADAS) \\
\hline 2006 & 636800 \\
\hline 2007 & 636800 \\
\hline 2008 & 700000 \\
\hline 2009 & 1345410 \\
\hline 2010 & 1755000 \\
\hline 2011 & 1755000 \\
\hline 2012 & 1710000 \\
\hline 2013 & 1710000 \\
\hline 2014 & 1426250 \\
\hline 2015 & 1385500 \\
\hline
\end{tabular}

Fonte: Produção Agrícola Municipal, IBGE, 2019. Organização: TAMBORIN, C. V.

Observar-se que no período analisado, tanto a área cultivada quanto a quantidade de cana-de-açúcar produzida tiveram acréscimos importantes, sendo $326,64 \%$ para a área em $\mathrm{km}^{2}$ e 277,64\% para a produção em toneladas.

A partir da exposição dos dados do SIDRA-IBGE no período de 11 anos, é possível observar que houve um aumento considerável na quantidade de área plantada de cana-de-açúcar na maioria dos municípios da microrregião, sendo que apenas em Delta houve, tanto na área plantada quanto na quantidade colhida, uma redução de $13,28 \%$.

Outro fato importante a se destacar a partir da análise dos dados do SIDRAIBGE, é que dentro do corte temporal estipulado na pesquisa, houve um aumento bem expressivo, tanto de área plantada, quanto da quantidade colhida, em municípios que não abrigam plantas de usinas sucroalcooleiras em seu território, como é o caso dos municípios de Água Comprida e Veríssimo. 


\section{TERRITÓRIOS (R)EXISTENTES NO PROCESSO DE TERRITORIALIZAÇÃO DA CANA DE AÇÚCAR}

A ciência geografia tem insistido no debate sobre território para teorizar os processos de reocupação do espaço. Assim, quando apresentamos a ampliação das lavouras de cana-de-açúcar, explicitamos que esse fenômeno ocorre sobre o território e as territorialidades já existentes.

Raffestain (1993) afirma que o território é um espaço onde se projetou um trabalho, seja energia e informação, e que, por consequência, revela relações marcadas pelo poder. O autor, afirma ainda que território se apoia no espaço, mas não é o espaço. É uma produção a partir do espaço. Ora, a produção, por causa de todas as relações que envolve, se inscreve num campo de poder [...] (RAFFESTIN, 1993). Neste sentido, podemos levar em consideração os poderes que as usinas sucroalcooleiras detêm onde são inseridas, pois elas reúnem as condições de transformar o espaço e consequentemente a paisagem que a circunda, ultrapassando limites municipais e estaduais.

A partir dos trabalhos de campo realizados na área de estudo percebemos que as usinas sucroalcooleiras se tornaram detentoras de poder político e econômico. Elas agem estabelecendo controle sob o entorno onde estão localizadas, afetando a produção de outras práticas socioprodutivas. Efetivamente acabam transformando as dinâmicas territoriais, tornando a produção de cana-de-açúcar um conjunto de atividades que acontece a partir de um amplo suporte social, econômico, político, estrutural, financeiro e tecnológico.

Contudo, a ideia de território nem sempre está ligado diretamente com a concepção de poder. Na área de estudo percebemos que antigos moradores apesar do poder hegemônico das usinas, continuam comparecendo nas paisagens rurais dos municípios, sobretudo, a partir das suas persistências na pecuária leiteira.

Na microrregião de Uberaba é possível perceber reações a territorialização da monocultura da cana, quando observamos aquilo que está oculto nos processos de avanços daquela cultura, principalmente em áreas de pastagens. 
“A cana é um problema para a gente que mexe com o gado de leite. Ela faz aparece uma mosca que não deixa as vacas come. Depois tem o avião que passa jogando um produto que seca tudo, até o pasto. Dai o jeito foi reclama e pedi providência"4

Assim, nos territórios da pecuária leiteira, há reações importantes derivadas dos seus impactos na alimentação e produção do rebanho leiteiro. Sendo importante verificar quantitativamente o avanço das lavouras de cana afetam a produção de leite de vaca na microrregião.

Os dados reunidos no quadro 1 indicam que a produção de leite na microrregião de Uberaba, diminuiu consideravelmente no período analisado. Tal fato indica situações de tensão entre os envolvidos nos processos produtivos de cana e leite. Certamente o poder político e econômico do setor sucroalcooleiro, ascendeu mais do que a produção de leite na microrregião.

\footnotetext{
${ }^{4}$ Fala de um camponês descrevendo os problemas decorrentes do cultivo de cana-de-açúcar e os jeitos de reação/reivindicação de seus direitos ao espaço. Veríssimo, 2018.
} 
Quadro 1: Relação Produção De Leite De Vaca (Mil litros) Entre 2006 a 2016

\begin{tabular}{|l|l|l|l|l|l|l|l|l|l|l|l|}
\hline $\begin{array}{l}\text { Município - } \\
\text { Estado MG }\end{array}$ & $\mathbf{2 0 0 6}$ & $\mathbf{2 0 0 7}$ & $\mathbf{2 0 0 8}$ & $\mathbf{2 0 0 9}$ & $\mathbf{2 0 1 0}$ & $\mathbf{2 0 1 1}$ & $\mathbf{2 0 1 2}$ & $\mathbf{2 0 1 3}$ & $\mathbf{2 0 1 4}$ & $\mathbf{2 0 1 5}$ & $\mathbf{2 0 1 6}$ \\
\hline Água Comprida & 6579 & 6486 & 7370 & 6844 & 6412 & 6937 & 6272 & 5267 & 5100 & 3241 & 3801 \\
\hline Campo Florido & 17245 & 17956 & 18779 & 18141 & 17357 & 19945 & 20090 & 19562 & 14350 & 12775 & 13870 \\
\hline Conceição das Alagoas & 15120 & 14898 & 15735 & 15370 & 14705 & 17396 & 15610 & 17236 & 20155 & 18900 & 14283 \\
\hline Conquista & 11219 & 11319 & 0806 & 10005 & 9639 & 11668 & 10514 & 10509 & 11290 & 9600 & 9375 \\
\hline Delta & 2105 & 2058 & 047 & 1445 & 1400 & 1751 & 1447 & 1203 & 991 & 921 & 840 \\
\hline Uberaba & 73564 & 73425 & 6665 & 76778 & 73458 & 74185 & 74100 & 68980 & 68670 & 55152 & 45152 \\
\hline Veríssimo & 14896 & 14931 & 4021 & 13779 & 14226 & 15160 & 12254 & 13470 & 19710 & 19890 & 14740 \\
\hline
\end{tabular}

Fonte: Pesquisa da Pecuária Municipal, IBGE, 2019. Organização: TAMBORIN, C. V.

Os dados presentes no quadro 1, possibilitam observar que no período entre 2006 e 2016 houve uma diminuição da produção de leite de Vaca (Mil litros) em todos os municípios da microrregião de Uberaba. No Município de Uberaba a produção de leite apresenta queda de 73564 para 45152 naquele período, tendo uma redução de 38,62\%. No Município de Conquista, a produção de leite de vaca era de 11219 em 2006, e em 2016, a produção contabilizou 9375 litros, diminuindo em 16,43\%. Delta, em 2006 apresentava uma produção de 2105 litros, e em 2016 atinge apenas 840 litros, registrando queda de 60\%. O município de Campo Florido também apresenta queda de 19,55\% na produção leiteira, sendo que em 2006, a produção atingiu 17245 litros de leite e em 2016, retrai para 13870 litros. Veríssimo, apresenta variações na produção de leite durante todo o período, contudo em 2006 a produção era de 14896 e em 2016, atinge 14740 litros, apresentando uma diminuição de 1,04\%. Água Cumprida em 2006 teve uma produção de 6579, no final do período essa produção chegou a 3801, tendo uma diminuição de 42,22\%. Seguindo também a situação de queda na produção leiteira, o Município de Conceição das Alagoas, passou de 15120 em 2006 para 14283 litros de leite em 2016, registrando queda de $8 \%$.

Contudo, a variação na produção de leite pode ter outros motivadores. No entanto, é a partir dos dados da Pesquisa da Pecuária Municipal, que se analisa as relações entre a queda na produção de leite e a territorialização da cana-de-açúcar. 
No município de Uberaba encontram-se duas usinas sucroalcooleiras. Suas inaugurações ocorrem no ano de 2015. Percebe-se que a produção de leite se manteve próximo dos 7000o, tendo sua queda mais significativa entre os anos de 2012 e 2013. Nesses mesmos anos, a área plantada de cana-de-açúcar aumentou de 60000 ha em 2013, para 81000 há em 2014, o que pode justificar a diminuição da produção de leite, pois as áreas de pastagens comparecem, na microrregião como opção de arrendamento aos cultivadores de cana. 5

Em Conceição Das Alagoas encontra-se apenas uma usina sucroalcooleira, sendo fundada em 1996. Analisando os dados reunidos do quadro 1, entende-se que a produção de leite de vaca no município variou bastante, mas teve seu ápice em 2014, tendo uma produção de 20155, porém, dois anos depois, os produtores de leite obtiveram a sua menor produção no período analisado , ou seja, 14283 litros de leite. Os dados de área plantada de cana-de-açúcar tiveram a mesma tendência daquela registrada no município de Uberaba. No município, entre os anos de 2014 e 2016, a área plantada aumentou de 38000 ha, para 45000 ha. podendo justificar a diminuição da produção de leite.

Delta é outro município de microrregião que também abriga uma planta industrial de usina sucroalcooleira. O município teve seu ápice de produção de leite, dentro do período, em 2006, com produção de 2105. Depois daquele ano, a quantidade de produção de leite caiu continuamente, até chegar em 2016 com uma produção de 840 litros. Com relação a área plantada com cana-de-açúcar, Delta é o único município que tem uma diminuição de área (entre 2006 e 2016). Contudo, mesmo havendo variações durante o período estudado, a área plantada foi de 4080 ha em 2015, para 5297 há em 2016.

Campo Florido, desde 2005, abriga em seu território uma usina sucroalcooleira. A produção de leite de vaca no município variou bastante durante os dez anos do recorte temporal, mas teve seu ápice em 2014, tendo uma produção de 20090 litros de leite. Em 2016, registra-se a menor produção de leite, sendo apenas de 14283 litros. No município a área cultivada com cana-de-açúcar que era de 18500 há em 2006 passa para 26000 em 2016 sendo que em 2014 registra-se a maior área plantada, a qual somou 29930 ha..

\footnotetext{
${ }^{55}$ Essas informações foram obtidas em trabalho de campo, quando questionamos sobre as áreas de arrendamento destinadas ao cultivo da cana-de-açúcar. As respostas, em geral, indicavam áreas de pastagem degradadas.
} 
Conquista também apresenta uma usina sucroalcooleira em seu território. $\mathrm{O}$ ápice de produção de leite ocorrer em 2011, tendo uma produção de 11668 litros de leite. No recorte temporal estudado, houve bastante variação, mas em 2016, teve o seu menor registro de produção leiteira, sendo de 9375 litros. Em relação a área plantada, destaca-se que a partir de 2011, a área plantada teve uma tendência de aumento, alcançando 21200 ha.

O município de Veríssimo, diferente daqueles já analisados, não abriga usinas sucroalcooleiras em seu território, e sua produção de leite teve pouca variação dentro do recorte temporal definido. O ápice da produção de leite ocorreu em 2011, com uma produção de 15160 litros, porém, em 2012, registra-se a sua menor produção, sendo de 12254 litros. A área plantada no município era de 8000 há em 2006, passou para 9000 ha em 2016.

Água Cumprida, também não abriga uma usina sucroalcooleira em seu território, teve seu auge de produção de leite de vaca em 2007, com uma produção registrada de 7370 litros. Nos anos seguinte, houve registros de queda da produção. Em relação a área plantada em 2006 somava 7960 ha, elevando-se para 26000 ha

No período analisado, considerando-se a redução na produção de leite e também o aumento da área plantada em cana-de-açúcar, a territorialização daquela cultura na microrregião, apresenta como desafio aos produtores de leite a sua reestruturação, principalmente em municípios onde ocorre a inserção de usinas sucroalcooleiras. Destaca-se o caso de Uberaba, que teve a maior diminuição da produção, seguida por Conceição Das Alagoas, Campo Florido e Conquista. Nestes municípios percebe-se que houve uma tendência da diminuição da produção de leite, enquanto houve um aumento considerável da área plantada de cana-de-açúcar.

\section{CONSIDERAÇÕES FINAIS}

Com o desenvolvimento da pesquisa, sobretudo, a partir das incursões ao campo, foi possível compreender a dinâmica espacial provocada a partir do monocultivo da cana-de-açúcar. Trata-se de práticas agrícolas que datam desde a reocupação/descobrimento do Brasil, e que continua tendo um forte apelo econômico, tanto nacional quando internacional. Em Minas Gerais a inserção da cana-de-açúcar fez com que o estado fosse um dos maiores produtores do país, e isso se deu a partir de inúmeros incentivos, econômicos, políticas, e parcerias público-privados, que 
juntamente com a qualidade, tanto do solo quanto do clima, possibilitaram que a macrorregião do Triângulo Mineiro e consequentemente a microrregião de Uberaba, se tornassem grandes praticantes daquela monocultura.

A Microrregião de Uberaba é formada por sete municípios, sendo que em cinco deles existe a presença de usinas sucroalcooleiras em seus territórios. A partir da análise dos dados da Produção Agrícola Municipal, provenientes do SIDRA IBGE, entre os anos de 2006 e 2016, percebeu-se que houve um aumento significativo na área ocupada com lavouras de cana-de-açúcar. Nos municípios que formam a microrregião, principalmente onde se encontram instaladas as plantas das usinas sucroalcooleiras, que é o caso dos municípios de Uberaba, Delta, Conceição das Alagoas, Conquista e Campo Florido, os impactos na produção de leite, em geral, é ainda maior que nos demais municípios.

Foi observando também, que em municípios onde não se encontram usinas sucroalcooleiras, sendo estes: Água Comprida e Veríssimo houve um aumento considerável na área plantada de cana-de-açúcar, reafirmando a ideia de que no cultivo de cana não existe fronteiras.

A partir dos dados de produção de leite provenientes da Pesquisa da Pecuária Municipal, a partir dos dados do Sidra/IBGE, percebeu-se como que o processo de territorialização da cana-de-açúcar se reproduz no espaço e gera tensões com outras culturas. Isso aconteceu principalmente em municípios onde houve a inserção de usinas sucroalcooleiras, que é o caso de Uberaba, Conceição Das Alagoas, Campo Florido e Conquista.

O cultivo da cana-de-açúcar e seu processamento a partir de usinas sucroalcooleiras se torna um agente de poder propagando a sua territorialização em espaços já ocupados. Trata-se de uma reocupação a partir de uma produção que ocorre alterando paisagens e a vida nos lugares. Tudo ocorre de forma tensa, pois impacta aqueles que praticam outros cultivos e modo de vida. A territorialização também se dá, quando houve a inserção e o funcionamento de usinas de processamento sucroalcooleiro em alguns municípios da microrregião, e que mesmo tendo algumas exceções, percebe-se que tais usinas presam, principalmente, o seu lucro, praticando a tecnificação dos processos produtivos, terceirização do trabalho, arrendamento de terras e ampliando a produção de derivados da cana. No caso da pecuária leiteira, compreende-se a necessidade urgente de políticas públicas que possibilitem as famílias se reinventarem para continuarem existindo como produtores de leite. 


\section{REFERENCIAS BIBLIOGRÁFICAS}

BRITO, Jorge Luís Silva; DOS REIS, Laís Naiara Gonçalves. MAPEAMENTO DAS ÁREAS DE CONVERSÃO DO USO DA TERRA PARA CANA-DE-AÇÚCAR NA MESORREGIÃO FO TRINAGULO MINEIRO/ALTO PARANAÍBA-MG POR MEIO DE IMAGENS TM/LANDSAT. Caminhos de Geografia, v. 13, n. 41, 2012.

CARVALHO, Eduardo Rozetti, de et al. Transformações socioterritoriais do capital sucroalcooleiro em Iturama. Pontal do Triângulo Mineiro. 2009.

CLEPS, JO CLEPS J. A TERRITORIALIZAÇÃO DA PRODUÇÃO AGROINDUSTRIAL CANAVIEIRA NA MESORREGIÃO DO TRIÂNGULO MINEIRO/ALTO PARANAÍ BA. Horizonte Científico, 2012.

DE SOUZA, Andreza GOMES; JUNIOR, João CLEPS. EXPANSÃO DA CANA-DEAÇÚCAR NO TRIÂNGULO MINEIRO E OS EFEITOS SOBRE A AGRICULTURA FAMiliar E O TRABALHO RURAL. Revista Tópos, v.3, n.2, p. 8-35,2009. GONÇALVES, D. B. Considerações sobre a expansão recente da lavoura canavieira no Brasil. Informações Econômicas, SP, v.39, n.10, out. 2009.

DELTA SUCROENERGIA, 2020. Disponível em:< http://www.deltasucroenergia.com.br/frontend/> Acesso em: 31 ago. 2020

IBGE, Censo Demográfico. Disponível em:< https://censo2010.ibge.gov.br/> Acesso em: 29 out. 2019.

IBGE. Cidades. Disponível em:< https://cidades.ibge.gov.br/> Acesso em: o1 set. 2020.

IBGE. Sidra. Pesquisa da Pecuária Municipal. Disponível em:< https://sidra.ibge.gov.br/Tabela/74>. Acesso em: 29 out. 2019.

IBGE. Sidra. Produção Agrícola Municipal. Disponível em:< https://sidra.ibge.gov.br/Tabela/1612>. Acesso em: 29 out. 2019.

INÁCIO, Jaqueline Borges. SANTOS, Rossevelt José. Contradições e tensões no processo de expansão do setor sucroenergético em Iturama-MG. 2014.

INÁCIO, Jaqueline JBI Borges; SANTOS, Rossevelt José. A EXPANSÃO CANAVIEIRA NO MUNICÍPIO DE DELTA-MG: "ILHADOS PELOS CANAVAIAIS". Caminhos da Geografia, v.14, n. 48, 2013.

RAFFESTAIN, Claude. Por uma geografia do poder. Tradução de Maria Cecília França. São Paulo: Ática, 1993 
SEAPA, Secretaria de Estado de Agricultura, Pecuária e Abastecimento do Estado de Minas Gerais. Cana de Açúcar. 2020. 30 slides Disponível em:< http://www.reformaagraria.mg.gov.br/images/documentos/perfil_cana_ago_2020 [1].pdf>Acesso em: 01 set. 2020.

SIAMIG, Associação das Indústrias Sucroenergéticas de Minas Gerais. Análise do setor sucroenergético na região do Triângulo Mineiro, 2018. Disponível em:< http://www.siamig.com.br/uploads/ed56a2350c250d7d766e2b741be95489.pdf> Acesso em: 01 set. 2020.

\section{USINA}

\section{CURURIPE,} 2020.

Disponível

em:< http://www.usinacoruripe.com.br/institucional\#unidades $>$ Acesso em: 31 ago. 2020 USINA UBERABA S.A, 2020. Disponível em:< https://www.canaverde.com.br/uberaba-usina-uberaba/> Acesso em: 31 ago. 2020 USINA VELE DO TIJUCO, 2020 Disponível em:< http://www.cmaa.ind.br/pt/> Acesso em: 31 ago. 2020

ZANZARINI, R. M. SANTOS, Rossevelt José. A expansão da cana-de-açúcar no Triângulo Mineiro- Uma Análise das alterações de cultivo. Araguari, MG, 2008. 